\title{
Gifts and influence: Conflict of interest policies and prescribing of psychotropic medications in the United States
}

\author{
Marissa King ${ }^{\text {a, * }}$, Peter S. Bearman ${ }^{b}$ \\ a Yale School of Management, Yale University, United States \\ ${ }^{\mathrm{b}}$ Department of Sociology, Columbia University, United States
}

\section{A R T I C L E I N F O}

\section{Article history:}

Received 12 August 2015

Received in revised form

30 October 2016

Accepted 7 November 2016

Available online 9 November 2016

\section{Keywords:}

Conflicts of interest

Mental health

Marketing

Pharmaceuticals

\begin{abstract}
A B S T R A C T
The pharmaceutical industry spends roughly 15 billion dollars annually on detailing - providing gifts, information, samples, trips, honoraria and other inducements - to physicians in order to encourage them to prescribe their drugs. In response, several states in the United States adopted policies that restrict detailing. Some states banned gifts from pharmaceutical companies to doctors, other states simply required physicians to disclose the gifts they receive, while most states allowed unrestricted detailing. We exploit this geographic variation to examine the relationship between gift regulation and the diffusion of four newly marketed medications. Using a dataset that captures 189 million psychotropic prescriptions written between 2005 and 2009, we find that uptake of new costly medications was significantly lower in states with marketing regulation than in areas that allowed unrestricted pharmaceutical marketing. In states with gift bans, we observed reductions in market shares ranging from $39 \%$ to $83 \%$. Policies banning or restricting gifts were associated with the largest reductions in uptake. Disclosure policies were associated with a significantly smaller reduction in prescribing than gift bans and gift restrictions. In states that ban gift-giving, peer influence substituted for pharmaceutical detailing when a relatively beneficial drug came to market and provided a less biased channel for physicians to learn about new medications. Our work suggests that policies banning or limiting gifts from pharmaceutical representatives to doctors are likely to be more effective than disclosure policies alone.
\end{abstract}

(C) 2016 Elsevier Ltd. All rights reserved.
Pharmaceutical companies invest heavily in marketing. Between 1990 and 2008, pharmaceutical expenditures on marketing increased more than six-fold from $\$ 3$ billion dollars to $\$ 20.5$ billion dollars (Congressional Budget Office, 2009). A practice commonly known as detailing, in which drug company representatives make sales calls to physicians and provide them with information, free samples, meals, and gifts, accounted for the majority of promotional expenses. Collectively, pharmaceutical companies spent $\$ 15.7$ billion dollars on detailing in 2011 or roughly $\$ 19,000$ for every physician in the United States (Kaiser Family Foundation, 2013; Pew Charitable Trusts, 2013).

Amidst growing concern about potential conflicts of interests generated by detailing, a host of states, medical schools, and interest groups within the U.S. began to advocate for policies to regulate interactions between physicians and pharmaceutical

\footnotetext{
* Corresponding author.

E-mail addresses: marissa.king@yale.edu (M. King), psb17@columbia.edu (P.S. Bearman).
}

representatives (Gorlach and Pham-Kanter, 2013; King et al., 2013). Efforts to transform the pharmaceutical industry have taken a variety of forms ranging from self-regulation to laws prohibiting physicians from receiving gifts. Academic medical centers have implemented policies to limit interactions between students and faculty and pharmaceutical representatives. States adopted laws regulating interactions between pharmaceutical representatives and physicians ranging from bans on gift giving to disclosure of gifts and payments. Finally, the Physician Payments Sunshine Act requires all drug manufacturers to publicly disclose financial relationships with physicians including gifts and meals. Surprisingly, little empirical research has examined the relative efficacy of these various policies.

While one might think that regulation of detailing should have obvious and strong effects on physician behavior, the canonical expectation from social psychology is that disclosures and gift restrictions are unlikely to be effective (Dana and Loewenstein, 2003; Sah and Fugh-Berman, 2013). Dana and Loewenstein argue, for example, that "limiting gift size, educational initiatives, and mandatory disclosure are unlikely to eliminate bias because they 
rest on a faulty model of human behavior" (Dana and Loewenstein, 2003:254). Gift restrictions are thought to be ineffective because even small gifts can create unconscious biases and disclosure can produce moral licensing, which perversely increases bias. Given the literature, it is not immediately obvious what effect, if any, regulations will have on new drug diffusion.

Recent empirical research has found that medical school policies limiting or prohibiting detailing lead to lower rates of new drug uptake (King et al., 2013), higher rates of generic prescribing (Epstein et al., 2013), and reduced off-label prescribing (Larkin et al., 2014). While this work has significantly advanced our understanding about the impact of medical schools' conflict of interest policies, three gaps remain in the existing literature. First, the comparative efficacy of various policy strategies-gift bans, gift restrictions, and disclosure policies-has received little attention. Second, it is unknown whether policies implemented at the state or federal level, rather than academic institutions, will be associated with prescribing patterns. Academic institutions, unlike states, have considerable control over detailer's access to providers and substantial monitoring and enforcement capacity. Finally, prior research has not examined whether physicians have and use alternative mechanisms to learn about efficacious medications when detailing is restricted. In places where detailing is limited or prohibited, it is imperative that physicians have an alternative way to learn about new effective medications. We address this issue by examining whether physician peer networks acted as alternative source of information about clinically advantageous medications when restrictions on pharmaceutical detailing existed. Prior research has found that peer networks influence physician prescribing behavior (Coleman et al., 1957; Manchanda et al., 2008) making network-based social learning a promising substitute for marketing.

To preview our main findings, we show that policies banning, limiting, and requiring disclosure of gifts to physicians were associated with lower prescribing rates of newly marketed medications. We observed significantly lower prescribing rates in states with gift bans and gift limits, than in states that relied on non-public disclosure alone. In states that ban gift-giving, peer influence substituted for pharmaceutical detailing when a relatively advantageous drug came to market.

\section{Background}

\subsection{State level pharmaceutical marketing regulation}

Eight states had adopted laws regulating pharmaceutical marketing by 2009. These state laws can be divided into three categories: (1) states that required disclosure of payments and gifts to physicians but do not limit or ban gifts, (2) states that required companies to adopt and comply with codes of conduct developed by the Pharmaceutical Research and Manufacturers of America, which limits gifts, and (3) states with both statutory gift bans and publicly available disclosure requirements (Gorlach and PhamKanter, 2013).

Vermont, Massachusetts and Minnesota banned most gifts to physicians and had the most comprehensive disclosure requirements for non-prohibited payments. Gifts, according to Vermont law, are defined as "anything of value provided for free to a health care provider" (V.SA. 4361a). Minnesota introduced the first state-level regulation prohibiting gifts in 1993. The legislation, which remains among the most stringent in the United States, banned gifts totaling $\$ 50$ or more in a given year from a single company. Similar legislation requiring mandatory reporting of payments exceeding $\$ 25$ was enacted by Vermont in 2002 . This legislation was subsequently strengthened in 2009 to include a ban on all gifts, including food, to health care professionals. In 2009, Massachusetts implemented regulation restricting payments and gifts and establishing a mandatory reporting requirement. Honoraria, consulting payments, clinical trials, research funding, samples, and educational materials are not considered gifts but must be disclosed. Disclosure data are publicly available and identify individual physicians.

Three states-Maine, West Virginia, and Washington D.C.required pharmaceutical companies to report aggregated marketing expenditures to the state. Disclosure laws typically exempted small gifts, reimbursements for clinical education, remuneration for conducting clinical trials, and drug samples. Unlike data from Minnesota, Vermont, and Massachusetts, the disclosure data from these three states is not readily available via public websites.

California and Nevada mandated that pharmaceutical companies adopt and comply with the guidelines developed by the Pharmaceutical Research and Manufactures of America (PhRMA) (National Conference of State Legislatures (2013); Gorlach and Pham-Kanter, 2013). PhRMA's Code on Professional Interactions with Health Care Professionals prohibits entertainment and recreational items, as well as gifts not related to patient care or education. The guidelines allow for meals accompanied by educational presentations and discussions, as well as educational gifts of $\$ 100$ or less per item. Payments or gifts that fall outside of the guidelines do not have to be disclosed.

To examine how regulatory environments shaped drug diffusion processes, we classified states by the strength of their regulation and assigned them to one of four groups: (1) states with gift bans and publicly available disclosure data, (2) states with codes of conduct and gift restrictions, (3) states with disclosure requirements, and (4) states without marketing regulation. Since Massachusetts and Connecticut adopted regulation after the study period, they are conservatively included in the set of states with "no policy."

\subsection{Mental health medications}

Mental health medications are currently among the best-selling and most heavily marketed classes of drugs in the United States. One in five adults in the United States received a mental health medication in 2010. In that year, sales of antidepressant, antipsychotic, and stimulant medications yielded close to $\$ 35$ billion dollars and accounted for $11.4 \%$ of U.S. spending on pharmaceuticals (IMS Incorporated 2010). These three drug classes are also among the top five most heavily detailed drug classes (Congressional Budget Office, 2009). Given the importance of these classes of medications to the pharmaceutical industry, our study focuses on newly introduced mental health medications.

Newly introduced drugs are substantially more expensive than the older alternatives and have contributed to both rising health care costs, as well as pharmaceutical revenues (Duggan, 2005). However, the majority of new drugs developed by pharmaceutical companies are minor variations on existing medications that offer few or no benefits over existing alternatives but often produce significant adverse reactions (Light and Lexchin, 2012). Over 90 percent of newly approved drugs have been found by independent assessors to offer no or minimal advantages over existing alternatives (Light et al., 2013). Thus, to assess the true impact of pharmaceutical marketing regulations, it is important to distinguish between clinically superior medications and minor variations.

With respect to efficacy, the FDA simply requires medications to be more efficacious than a placebo, even when effective drugs already exists. It does not mandate that companies compare the effectiveness of a newly introduced drug to existing alternatives in what are known as head-to-head drug trials. Since head-to-head 
trials are rarely conducted, determining how advantageous a new medication is necessitates compiling published and unpublished studies and clinical trials for all existing drugs in the class to assess relative drug efficacy, adverse events, and side effects. While the drugs examined in this study vary in their level of clinical benefit, none are radical breakthroughs in their class and all relied on active ingredients already available on the market.

Our analysis focuses on four mental health medications introduced during our study period: Vyvanse ${ }^{\mathrm{TM}}$ (stimulant), InvegaTM (antipsychotic), Pristiq ${ }^{\mathrm{TM}}$ (antidepressant) and Cymbalta ${ }^{\mathrm{TM}}$ (antidepressant). Cymbalta was introduced four months prior to the beginning of our dataset; all other medications were introduced during the study window. No other oral mental health medications were introduced during the study period. These medications are ideally suited to studying new drug diffusion since they vary in how clinically beneficial they are relative to existing alternatives within the class.

\subsubsection{Vyvanse}

Vyvanse is a stimulant used to treat attention-deficit/ hyperactivity disorder. While Vyvanse relies on active ingredients that are already available on the market, the process by which it is metabolized makes it less prone for abuse and longer-lasting than other medications. The reduced potential for abuse is an important development within the class since stimulants are among the most commonly misused prescription medications. The Medical Letter, a publication described by the then deputy editor of the New England Journal of Medicine as producing "prescribing recommendations that are free of pharmaceutical influence" (Zuccotti in Valentino, 2004), reported of Vyvanse that, it "has no euphoric effects if given IV [intravenously] or taken intranasally and is thought to have less potential for abuse than amphetamine itself. The duration of action of lisdexamfetamine (Vyvanse) is longer than that of other amphetamine preparations, which may be an advantage for use in working adults." Vyvanse's advantages over other medications in its class have also been established in two meta-analyses that synthesized the results of 32 (Roskell et al., 2014) and 28 clinical trials (Stuhec et al., 2015), respectively. As Stuhec et al. (2015) wrote, "The results suggest that lisdexamfetamine [Vyvanse] has the best benefit risk balance and has promising potential for treating children and adolescents with ADHD."

\subsubsection{Cymbalta}

Cymbalta (duloxetine) is a serotonin and norepinephrine reuptake inhibitor first approved to treat major depressive disorder in August of 2004. At the time of our study, it was the only antidepressant approved by the FDA to treat neuropathic pain. In June 2008, Cymbalta received an indication for treatment of Fibromyalgia. Describing Cymbalta's utility for treating Fibromyalgia, The Medical Letter wrote it "appears to be effective in reducing the symptoms of Fibromyalgia" and "has the advantage of oncedaily dosing and possibly adding effective treatment for depression, which is common in patients with fibromyalgia" (Medical Letter 2008). A Cochrane Review of six trials that included 2200 participants found that Cymbalta was effective in treating both Fibromyalgia and painful diabetic peripheral neuropathy (Lunn et al., 2009). Pain and depression frequently co-occur with close to half of patients with depression reporting that they experienced some physical pain (Goesling, 2013). The ability to effectively treat pain and Fibromyalgia are important advantages Cymbalta has over other antidepressants.

\subsubsection{Pristiq and Invega}

While Cymbalta and Vyvanse have advantages over existing alternatives within their respective classes, Pritiq and Invega are structurally similar to existing medications and offer little or no known advantages. Both Pristiq and Invega are partially metabolized products of an existing drug. When a patient takes Invega, it is metabolized into risperidone which is already generically available. Similarly, Pristiq is converted into venlafaxine. As a result, Pristiq was described in the Medical Letter as having "no demonstrated clinical advantage over the parent compound." Similarly, Invega was found "to be similar to risperidone in effectiveness and adverse effects." Wyeth withdrew its application for marketing authorization for Pristiq in the European Union after concerns were expressed over its lack of efficacy and similarity to venlafaxine. Pristiq is not approved for use in the E.U (see Table 1).

As Table 2 summarizes, there were considerable differences in the advantageousness of these four drugs. While all four are mental health medications, they are not competitors since they treat different underlying conditions. Vyvanse had less potential for abuse than other stimulants and was also marketable to adults because of its long-lasting formulation. With an indication for pain, Cymbalta had a point of differentiation that was heavily marketed to gain market share. In contrast, both Pristiq and Invega offered no improvement over existing medications (see Table 3).

Table 1

Characteristics of policies regulating pharmaceutical marketing activity by state. Policies in Massachusetts and Connecticut went into effect after our study period.

\begin{tabular}{|c|c|c|c|c|c|c|c|}
\hline & \multicolumn{3}{|c|}{ Disclosure } & \multicolumn{2}{|c|}{ Gift Limit } & \multicolumn{2}{|c|}{$\begin{array}{l}\text { Gift Ban \& Public } \\
\text { Disclosure }\end{array}$} \\
\hline & DC & ME & WV & CA & NV & MN & VT \\
\hline Non-public Disclosure & $\bullet$ & $\bullet$ & $\bullet$ & & & & \\
\hline Statutory Gift Limits Based on PhRMA Code & & & & $\bullet$ & • & & \\
\hline Individual Payments to Physicians Publicly Available & & & & & & $\bullet$ & $\bullet$ \\
\hline Statutory Gift Ban & & & & & & • & • \\
\hline
\end{tabular}

Table 2

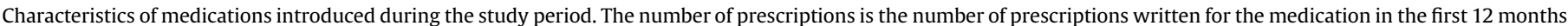

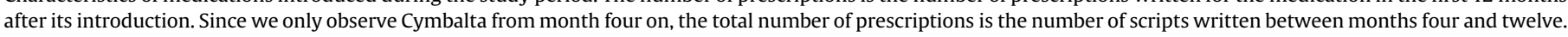

\begin{tabular}{|c|c|c|c|c|}
\hline Name & Class & Introduced & Prescriptions & Therapeutic Improvement \\
\hline Cymbalta & Antidepressant & $8 / 2004$ & $1,313,938$ & Indication for pain and Fibromyalgia. \\
\hline Vyvanse & Stimulant & $3 / 2007$ & $1,195,185$ & Less potential for abuse. Longer acting. \\
\hline Invega & Antipsychotic & $12 / 2006$ & 170,623 & Little or no improvement. \\
\hline Pristiq & Antidepressant & $2 / 2008$ & 573,298 & Little or no improvement. \\
\hline
\end{tabular}


Table 3

Negative binomial hurdle model of prescribing rates in the first year medication was on the market. Clustered standard errors are in parentheses. Exponentiated coefficients. ${ }^{* * *} \mathrm{p}<0.001,{ }^{* *} \mathrm{p}<0.01,{ }^{*} \mathrm{p}<0.05$.

\begin{tabular}{|c|c|c|c|c|}
\hline & \multicolumn{2}{|c|}{ New Clinical Benefits } & \multicolumn{2}{|c|}{ Minor Variations } \\
\hline & Vyvanse & Cymbalta & Invega & Pristiq \\
\hline \multicolumn{5}{|l|}{ Logistic } \\
\hline Gift Ban and Public Disclosure & $\begin{array}{l}0.52^{* * *} \\
(0.02)\end{array}$ & $\begin{array}{l}0.61^{* * *} \\
(0.02)\end{array}$ & $\begin{array}{l}0.60^{* * *} \\
(0.06)\end{array}$ & $\begin{array}{l}0.17^{* * *} \\
(0.02)\end{array}$ \\
\hline Gift Restriction & $\begin{array}{l}0.66^{* * * *} \\
(0.01)\end{array}$ & $\begin{array}{l}0.63^{* * *} \\
(0.01)\end{array}$ & $\begin{array}{l}0.69^{* * *} \\
(0.03)\end{array}$ & $\begin{array}{l}0.71^{* * *} \\
(0.02)\end{array}$ \\
\hline Disclosure & $\begin{array}{l}0.75^{* * *} \\
(0.03)\end{array}$ & $\begin{array}{l}0.94 \\
(0.03)\end{array}$ & $\begin{array}{l}0.82^{*} \\
(0.07)\end{array}$ & $\begin{array}{l}0.75^{* * *} \\
(0.04)\end{array}$ \\
\hline Graduation Year & $\begin{array}{l}1.01^{* * *} \\
(0.000)\end{array}$ & $\begin{array}{l}1.01^{* * *} \\
(0.000)\end{array}$ & $\begin{array}{l}1.00^{*} \\
(0.001)\end{array}$ & $\begin{array}{l}1.01^{* * *} \\
(0.000)\end{array}$ \\
\hline Volume of Competitor Drugs & $\begin{array}{l}1.08^{* * *} \\
(0.00)\end{array}$ & $\begin{array}{l}1.05^{* * *} \\
(0.00)\end{array}$ & $\begin{array}{l}1.02^{* * *} \\
(0.00)\end{array}$ & $\begin{array}{l}1.02^{* * *} \\
(0.00)\end{array}$ \\
\hline Cash (\%) & $\begin{array}{l}0.99^{* * *} \\
(0.00)\end{array}$ & $\begin{array}{l}1.00^{* * *} \\
(0.00)\end{array}$ & $\begin{array}{l}0.69 * * \\
(0.09)\end{array}$ & $\begin{array}{l}1.00^{* * *} \\
(0.00)\end{array}$ \\
\hline Medicaid (\%) & $\begin{array}{l}1.00^{* * *} \\
(0.00)\end{array}$ & $\begin{array}{l}1.00^{* * *} \\
(0.00)\end{array}$ & $\begin{array}{l}1.30^{* * *} \\
(0.06)\end{array}$ & $\begin{array}{l}0.98^{* * *} \\
(0.00)\end{array}$ \\
\hline General Practitioner & $\begin{array}{l}0.89^{* * *} \\
(0.01)\end{array}$ & $\begin{array}{l}0.98 \\
(0.01)\end{array}$ & $\begin{array}{l}0.47^{* * *} \\
(0.010)\end{array}$ & $\begin{array}{l}1.41^{* * *} \\
(0.013)\end{array}$ \\
\hline \multicolumn{5}{|l|}{ Negative Binomial } \\
\hline Gift Ban and Public Disclosure & $\begin{array}{l}0.68^{* * * *} \\
(0.04)\end{array}$ & $\begin{array}{l}0.67^{* * * *} \\
(0.03)\end{array}$ & $\begin{array}{l}0.75 \\
(0.14)\end{array}$ & $\begin{array}{l}0.43^{* * *} \\
(0.06)\end{array}$ \\
\hline Gift Restriction & $\begin{array}{l}0.92^{* *} \\
(0.03)\end{array}$ & $\begin{array}{l}0.91^{* * *} \\
(0.02)\end{array}$ & $\begin{array}{l}1.18^{*} \\
(0.10)\end{array}$ & $\begin{array}{l}0.88^{* * *} \\
(0.03)\end{array}$ \\
\hline Disclosure & $\begin{array}{l}0.85^{* * *} \\
(0.04)\end{array}$ & $\begin{array}{l}0.92 \\
(0.04)\end{array}$ & $\begin{array}{l}0.99 \\
(0.17)\end{array}$ & $\begin{array}{l}0.86 \\
(0.09)\end{array}$ \\
\hline Graduation Year & $\begin{array}{l}1.00^{* * *} \\
(0.00)\end{array}$ & $\begin{array}{l}1.00 \\
(0.00)\end{array}$ & $\begin{array}{l}1.00^{*} \\
(0.00)\end{array}$ & $\begin{array}{l}1.00 \\
(0.00)\end{array}$ \\
\hline Volume of Competitor Drugs & $\begin{array}{l}1.03^{* * *} \\
(0.00)\end{array}$ & $\begin{array}{l}1.02^{* * *} \\
(0.00)\end{array}$ & $\begin{array}{l}1.01^{* * *} \\
(0.00)\end{array}$ & $\begin{array}{l}1.01^{* * *} \\
(0.00)\end{array}$ \\
\hline Cash (\%) & $\begin{array}{l}0.99 * * * \\
(0.00)\end{array}$ & $\begin{array}{l}1.00^{* * *} \\
(0.00)\end{array}$ & $\begin{array}{l}0.61 \\
(0.21)\end{array}$ & $\begin{array}{l}1.00 \\
(0.00)\end{array}$ \\
\hline Medicaid (\%) & $\begin{array}{l}1.00^{* * * *} \\
(0.00)\end{array}$ & $\begin{array}{l}1.00^{* *} \\
(0.00)\end{array}$ & $\begin{array}{l}0.88 \\
(0.09)\end{array}$ & $\begin{array}{l}0.99^{* *} \\
(0.00)\end{array}$ \\
\hline General Practitioner & $\begin{array}{l}0.73^{* * *} \\
(0.01)\end{array}$ & $\begin{array}{l}0.72^{* * *} \\
(0.01)\end{array}$ & $\begin{array}{l}0.50^{* * *} \\
(0.14)\end{array}$ & $\begin{array}{l}0.84^{* * *} \\
(0.02)\end{array}$ \\
\hline N Physician Months & $3,733,755$ & $2,359,576$ & $1,614,599$ & $3,982,415$ \\
\hline
\end{tabular}

\section{Data and methods}

De-identified prescription data came from the IMS LifeLink ${ }^{\mathrm{TM}}$ LRx Longitudinal Prescription database. IMS obtains prescription information from approximately 33,000 retail pharmacies, food stores, independent pharmacies, as well as mass retailers. Over 60 percent of all prescriptions filled at retail outlets in the United States are included in the LRx data. During our study period, coverage of the LRx database ranged from 224,140,604 unique individuals who filled at least one prescription for any medication at the beginning of the study period to $233,592,728$ individuals at the end of the study period.

We focus on the 47,607,531 patients who received at least one prescription for an antidepressant, stimulant, or antipsychotic medication between January 1, 2005 and April 30, 2009. Of central interest is the prescribing behavior of the 916,338 physicians who wrote at least one prescription for an antidepressant, antipsychotic, or stimulant to one of these patients. The dataset captures at least one prescription for $80 \%(916,338 / 1,144,790)$ of physicians in the United States. The data is geographically representative and is representative by sex, age, and insurance status; it has been used in numerous publications within the medical literature (for examples see King et al., 2013).

Each prescription record contains a unique prescriber identification number, indicates how the prescription was paid for (Cash, Medicaid or Third Party insurance), and includes the co-payment for the prescription, the date dispensed, and the medication the prescription was written for. Using an encrypted prescriber identification number, it is possible to link prescriptions to information about the physician including the three-digit zip code in which the physician practiced, their specialty, the year they graduated medical school, and the medical school from which they received their degree.

\section{Analysis strategy}

The first goal of our analysis was to determine whether patterns of new drug uptake differed by drug across regulatory environments. To examine overall patterns of new drug penetration, we plotted the market share of each drug during the first year it was on the market. Market share was calculated by taking the total number of prescriptions for the focal drug and dividing it by the total number of prescriptions within that prescription drug class. Plots were constructed for each regulatory environment (1) states requiring disclosure, (2) states that limit gifts, (3) states that ban gifts, and (4) states with no pharmaceutical regulation.

\subsection{Regulatory environments}

After descriptively examining prescribing rates by regulatory regime, we estimated models examining the importance of different types of regulation on provider prescribing behavior using negative binomial hurdle models. A negative binomial hurdle is a modified count model in which counts are modeled in two stages. A logit model governs whether a count is zero or a positive value. If the zero hurdle is crossed and one or more prescriptions for the drug of interest were written in the focal month, then a negative binomial model is used. Using a hurdle model allows us to examine whether peer influence and marketing restrictions are more important when a physician is deciding whether to prescribe a drug at all (logit stage) or making a decision about prescribing intensity (negative binomial stage).

All models were estimated using physician-month as the unit of analysis, so there is one observation for each physician in each month a drug was prescribed within the focal medication class. Providers were considered eligible to prescribe a newly introduced medication and were included in our analysis if they wrote at least one prescription within the class during the focal month. For instance, a physician would be included in the Vyvanse analysis for May 2007 if at least one stimulant was prescribed in that month, regardless of what stimulant was prescribed.

Our analyses are limited to the first year each medication was on the market. Since all of the medications were introduced at different times, a four year window was necessary to capture the first year each medication was on the market. Standard errors were clustered by prescriber. Hurdle models only allow clustering on one dimension. Since the correlations within prescriber are of the greatest concern, we estimated models clustering by prescriber. As a robustness check we also estimated models clustering by state, which consistently produced smaller standard errors.

To examine the association between pharmaceutical regulation and physician prescribing, we included three indicator variables for policy type-(1) disclosure, (2) gift restriction, or (3) gift ban and public disclosure-using no policy as the reference category in our models. Based on the existing literature, we also included several physician characteristics as control variables: physician specialty, year of graduation from medical school, and insurance composition of physicians' patients. The models include a general practitioner indicator coded as " 1 " if the physician was a general practitioner and " 0 " otherwise. Insurance composition was characterized by the percent of patients with third-party insurance, which includes Medicare, percent paying with cash, and percent of patients 
covered by Medicaid in each physician's practice. The largest category, percent of patients with third-party insurance, was used as the reference category. We also include the physicians' prescribing volume of competitor drugs within the same class.

\subsection{Peer influence}

After establishing that prescribing patterns vary across regulatory environments, we wanted to examine whether peer influence substituted for marketing. In places where detailing is limited or prohibited, it is imperative that physicians have an alternative way to learn about new effective medications. Peer influence in our models is designed to capture peer-to-peer information sharing and exclude the possible influence of key opinion leaders which are another marketing tool used by pharmaceutical companies. We anticipated that peer effects would be strongest for new medications with benefits over existing alternatives in states with strict gift regulation.

To examine the importance of peer influence for each of the medications, we included the lagged prescribing volume of physicians who practice in the same three-digit zip code, attended the same medical school, graduated in the same year, and are of the same specialty as the focal physician. This was the most restrictive definition of "peer" available given our data structure, but also seems reasonable given the size of medical schools and the nature of medical practice. Using this definition, roughly $8 \%$ of prescribers had at least one peer. As we describe below, we also estimated our models using an alternative measure of peers based on patientsharing networks to assess the validity of our proxy for peer influence.

We assessed whether the importance of peer influence varied by regulatory environment, by including interactions between the policy variables and the volume of peer prescribing of the focal drug in the previous period. Invega and Pristiq were modeled solely with logit models since $97.1 \%$ and $96.4 \%$ of doctors in a given month wrote one or fewer prescriptions for these drugs, respectively. We included peer prescribing volume of competitor drugs in all our models. Finally, all models examining peer effects included the physician's lagged prescription volume of the focal drug. Incorporating the lagged prescribing volume of the drug of interest helps eliminate autocorrelation and takes into account that prescribing volumes at $t+1$ are likely a function of prescribing at time $t$. Standard errors are clustered by physician in the hurdle specifications and by physician and state in logit specifications. Logit and negative binomial models estimated with autoregressive error structures produced similar results and are available upon request.

After examining how peer influence and state regulatory policies shaped physician prescribing decisions, we calculated the predicted number of prescriptions written for each medication in the first year the product was on the market. Using the margins command in Stata, we generated predicted prescribing rates by policy regime based on estimates from negative binomial models for Vyvanse and Cymbalta and from logit models for Invega and Pristiq. In order to examine the importance of peer effects in each regulatory regime, we estimated predicted prescribing rates by regulatory regime with no peer prescribing of the focal drug and peer prescribing at one standard deviation above the mean prescribing of the focal drug. We present graphs comparing states with the most stringent marketing regulation to states without marketing regulation.

\subsection{Sensitivity analyses}

Marketing regulation, which is central to our analysis, helps us assess whether observed peers effects are being confounded by marketing efforts. If we observe stronger peer effects in states that limit pharmaceutical marketing, it is unlikely that our measure of peer influence is simply capturing marketing efforts. Moreover, including a lagged dependent variable (the prescribing rate of the focal drug in the previous period) in our analyses acts as a control for physician directed marketing since pharmaceutical companies allocate detailing primarily based on previous physician prescribing patterns.

To assess the adequacy of lagged prescribing volume as proxies for pharmaceutical marketing efforts, we conducted several additional sensitivity analyses. First, we estimated models with zip code fixed effects to assess whether our estimates of peer effects, which partially rely on co-location, could be capturing something that constantly impacted all physicians in the area, such as a successful detailer or key opinion leader. Models that included zip code fixed effects were stratified by regulatory environment. We also estimated models that included physician fixed effects to assess whether our results could arise from detailers targeting physicians who have a higher unobserved propensity to prescribe the focal medication due to characteristics that do not change over time, such as prior training or stable preferences, not captured in our models. Models with zip code or physician fixed effects were estimated using a negative binomial specification for Vyvanse and Cymbalta and as logit models for Invega and Pristiq. To ensure that our results are not capturing exposure to a time varying shock that occurred in the zip code such as a conference or activity of a key opinion leader, we generated simulated peers by randomly generating peers within three-digit zipcodes and re-estimated our models Finally, we re-estimated our models with an alternate measure of peers based on physician patient-sharing networks. (See Supplementary Appendix).

\section{Results}

First, with respect to sheer uptake of new drugs, we observe that prescribing rates of new medications were lower in states with detailing regulations than in states without marketing regulations. As shown in Fig. 1, prescribing rates for all four medications were highest in states with no marketing regulation and lowest in states that banned gifts to doctors.

\subsection{Regulatory environments}

Turning to the models examining regulatory strength and prescribing rates, we find further evidence that prescribing rates varied by state regulatory environment after controlling for physician level characteristics. Physicians in states with gift bans were $39 \%-83 \%$ less likely than their peers in non-regulated states to prescribe newly marketed medications. Gift ban odds ratios examining the likelihood that a physician would prescribe a new medication ranged from 0.61 (95\% C.I. 0.47-0.56) for Cymbalta to 0.17 (95\% C.I. 0.14-0.21) for Pristiq. Physicians in states with gift limits also had a lower propensity to prescribe than physicians in states without marketing restrictions. The odds-ratios for gift limits ranged from 0.63 (95\% CI: 0.61-0.65) for Cymbalta to 0.71 (95\% CI: 0.68-0.74) for Pristiq. Disclosure policies were associated with a significantly smaller reduction in prescribing relative to other types of regulation (OR Range: 0.75-0.94). For all four medications the coefficient for disclosure policies was significantly larger than the gift limit or gift ban coefficients (Wald-test: $\mathrm{p}<0.001$ ).

Gift bans and restrictions were also associated with prescribing intensity for the majority of medications were examined. Incidence rate ratios in the negative binomial stage of the regression ranged from 0.43 to 0.75 in states with gift bans and public disclosure. The 


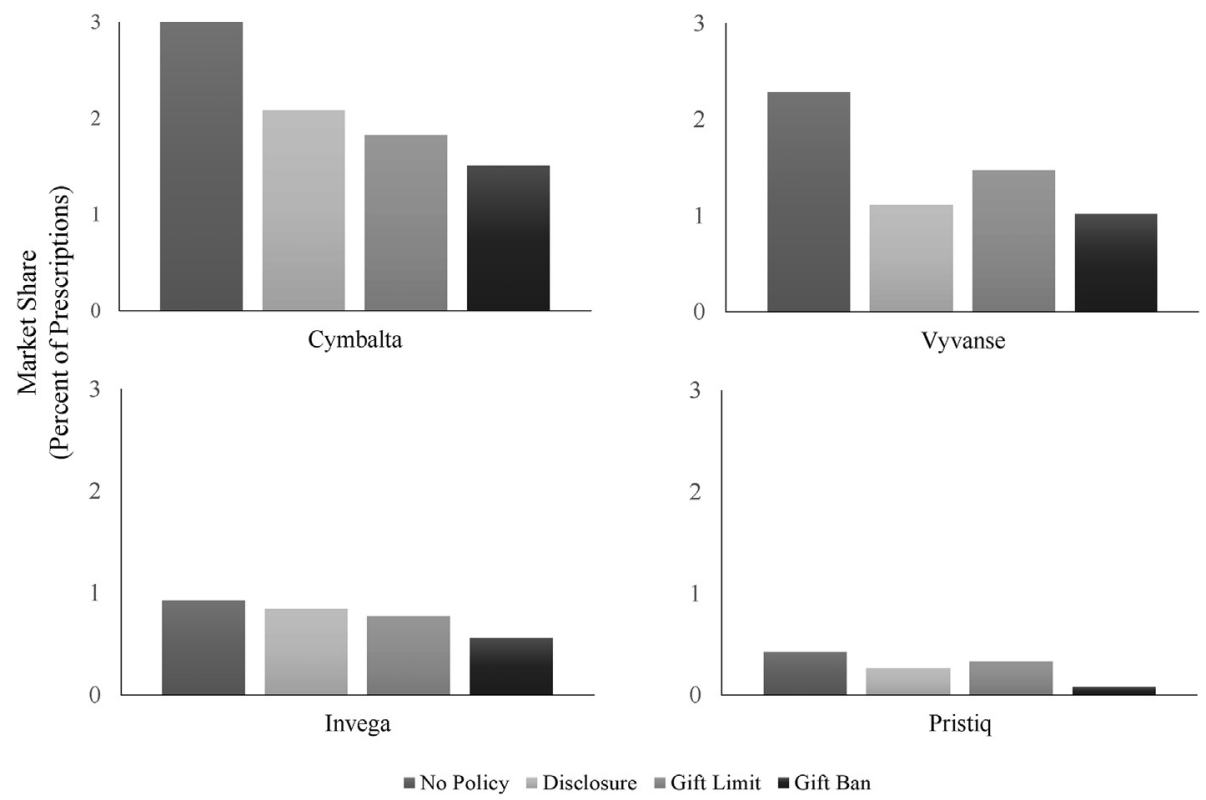

Fig. 1. Market shares of newly introduced medication during the first year on the market by regulatory environment.

insignificant and inconsistent coefficients for Invega in the negative binomial stage are unsurprising given that less than three percent of physicians wrote multiple prescriptions for Invega in a given month. Gift bans with public disclosure requirements for exempt items were significantly more likely than to other policy instruments to reduce prescribing levels of new medications (Wald-

Table 4

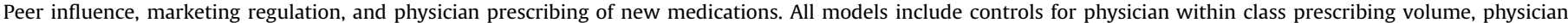

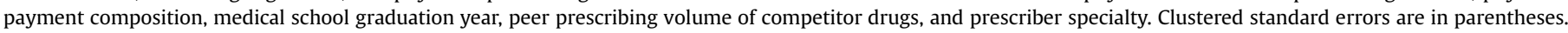
Exponentiated coefficients. ${ }^{* * *} \mathrm{p}<0.001,{ }^{* *} \mathrm{p}<0.01,{ }^{*} \mathrm{p}<0.05$.

\begin{tabular}{|c|c|c|c|c|}
\hline & \multicolumn{2}{|c|}{ New Clinical Benefits } & \multicolumn{2}{|c|}{ Minor Variations } \\
\hline & Vyvanse & Cymbalta & Invega & Pristiq \\
\hline \multicolumn{5}{|l|}{ Logit } \\
\hline Gift Ban and Public Disclosure & $\begin{array}{l}0.56^{* * *} \\
(0.050)\end{array}$ & $\begin{array}{l}0.68^{* * *} \\
(0.038)\end{array}$ & $\begin{array}{l}0.70^{*} \\
(0.100)\end{array}$ & $\begin{array}{l}0.25^{* * *} \\
(0.037)\end{array}$ \\
\hline Gift Restriction & $\begin{array}{l}0.72^{* * *} \\
(0.063)\end{array}$ & $\begin{array}{l}0.69^{* * *} \\
(0.033)\end{array}$ & $\begin{array}{l}0.70^{* *} \\
(0.088)\end{array}$ & $\begin{array}{l}0.61^{* * *} \\
(0.047)\end{array}$ \\
\hline Disclosure & $\begin{array}{l}0.88 \\
(0.125)\end{array}$ & $\begin{array}{l}0.80^{*} \\
(0.079)\end{array}$ & $\begin{array}{l}1.00 \\
(0.297)\end{array}$ & $\begin{array}{l}0.71 \\
(0.129)\end{array}$ \\
\hline Gift Ban and Disclosure*Peer Influence & $\begin{array}{l}1.11^{* * *} \\
(0.032)\end{array}$ & $\begin{array}{l}1.10^{*} \\
(0.042)\end{array}$ & $\begin{array}{l}0.79 \\
(0.224)\end{array}$ & $\begin{array}{l}0.48 \\
(0.289)\end{array}$ \\
\hline Gift Restriction *Peer Influence & $\begin{array}{l}1.05 \\
(0.032)\end{array}$ & $\begin{array}{l}0.99 \\
(0.014)\end{array}$ & $\begin{array}{l}1.08 \\
(0.077)\end{array}$ & $\begin{array}{l}1.09 \\
(0.076)\end{array}$ \\
\hline Disclosure*Peer Influence & $\begin{array}{l}1.13 \\
(0.098)\end{array}$ & $\begin{array}{l}1.02 \\
(0.029)\end{array}$ & $\begin{array}{l}0.55 \\
(0.270)\end{array}$ & $\begin{array}{l}1.26 \\
(0.156)\end{array}$ \\
\hline Peer Influence & $\begin{array}{l}1.02^{* * *} \\
(0.004)\end{array}$ & $\begin{array}{l}1.05^{* * *} \\
(0.004)\end{array}$ & $\begin{array}{l}1.02 \\
(0.015)\end{array}$ & $\begin{array}{l}1.07^{* * *} \\
(0.015)\end{array}$ \\
\hline Lagged Prescribing & $\begin{array}{l}7.60^{* * *} \\
(0.276)\end{array}$ & $\begin{array}{l}8.84^{* * *} \\
(0.203)\end{array}$ & $\begin{array}{l}11.87^{* * *} \\
(0.865)\end{array}$ & $\begin{array}{l}13.94^{* * *} \\
(0.569)\end{array}$ \\
\hline Negative Binomial & & & & \\
\hline Gift Ban and Public Disclosure & $\begin{array}{l}0.52^{* * *} \\
(0.097)\end{array}$ & $\begin{array}{l}0.84^{*} \\
(0.071)\end{array}$ & & \\
\hline Gift Restriction & $\begin{array}{l}0.98 \\
(0.120)\end{array}$ & $\begin{array}{l}0.93 \\
(0.058)\end{array}$ & & \\
\hline Disclosure & $\begin{array}{l}0.91 \\
(0.182)\end{array}$ & $\begin{array}{l}0.81^{*} \\
(0.084)\end{array}$ & & \\
\hline Gift Ban and Disclosure*Peer Influence & $\begin{array}{l}1.07^{*} \\
(0.037)\end{array}$ & $\begin{array}{l}1.05^{*} \\
(0.025)\end{array}$ & & \\
\hline Gift Restriction*Peer Influence & $\begin{array}{l}0.97 \\
(0.037)\end{array}$ & $\begin{array}{l}0.97 \\
(0.013)\end{array}$ & & \\
\hline Disclosure*Peer Influence & $\begin{array}{l}0.93 \\
(0.086)\end{array}$ & $\begin{array}{l}1.01 \\
(0.019)\end{array}$ & & \\
\hline Lagged Prescribing & $\begin{array}{l}1.08^{* * *} \\
(0.006)\end{array}$ & $\begin{array}{l}1.20^{* * *} \\
(0.007)\end{array}$ & & \\
\hline Peer Influence & $\begin{array}{l}1.02^{* * *} \\
(0.002)\end{array}$ & $\begin{array}{l}1.02^{* * *} \\
(0.003)\end{array}$ & & \\
\hline $\mathrm{N}$ & 215,445 & 208,072 & 133,466 & 316,986 \\
\hline
\end{tabular}



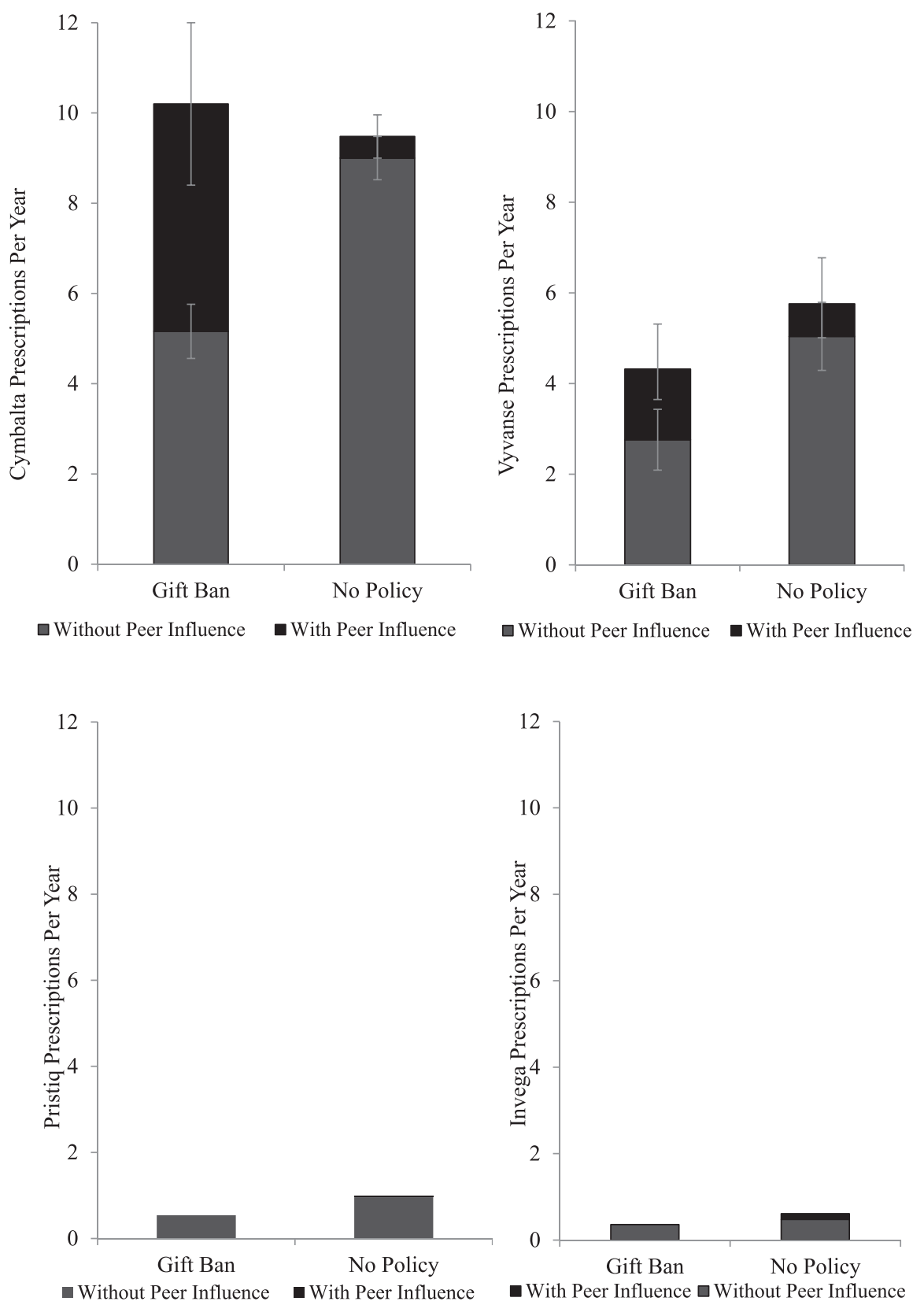

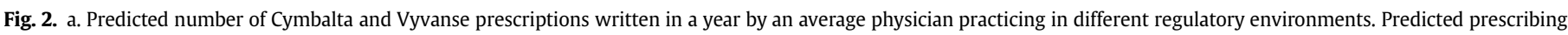

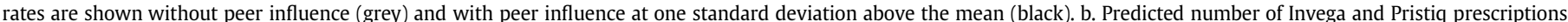

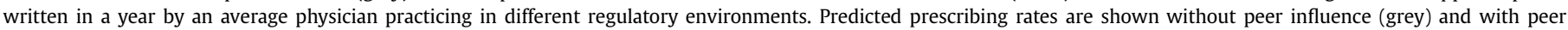
influence at one standard deviation above the mean (black). Differences are not significant at $\mathrm{p}<0.05$.

test: $\mathrm{p}<0.001$ ). Disclosure policies were not associated with prescribing volume for the majority of drugs we examined.

\subsection{Peer influence}

In Table 4, which includes peer influence, we again see that the odds of a physician prescribing a newly marketed medication were lower in states with gift bans. Here, we also observe a significant and positive coefficient for peer influence. For all medications except Invega, physicians were more likely to prescribe a newly marketed medication if their peers had prescribed it in the previous month. For clinically advantageous medications, peer influence was more important in states with gift bans than in states without marketing regulation. The odds ratio for the interaction between peer influence and gift bans for Cymbalta was 1.10 in the logistic stage of the hurdle model and the incidence rate ratio was 1.05 in the negative binomial stage. For Vyvanse, the interaction terms between peer influence and gift bans were 1.11 and 1.07 in the logit and negative binomial stages, respectively. Peer influence did not vary by regulatory environment for Invega and Pristiq.

To investigate the clinical significance of these findings, we generated predicted prescribing rates based on the models. As both Fig. 2a and b shows, baseline prescribing rates for all four medications (shown in grey) were lower in states with gift bans than in states with unrestricted pharmaceutical detailing. In the absence of peer influence, physicians typically wrote 5.2 Cymbalta 
prescriptions per year in states with gift bans and 9 prescriptions in states without regulation. However, once peer influence is taken into account (shown in black), physicians in states with gift bans prescribed an estimated 10.2 Cymbalta prescriptions per year. High levels of peer influence nearly doubled Cymbalta prescribing rates in gift ban states. In contrast, the addition of peer influence in states without marketing regulation had little impact on prescribing, adding less than one prescription per year. We observed a similar pattern for Vyvanse. In a world without peer influence, the average physician in gift ban states would write 2.8 Vyvanse prescriptions per year. This is considerably lower than the 5 prescriptions written by physicians in states without detailing restrictions. However, once peer influence is taken into account the prescribing rate of physicians in states with gift bans rises to 4.3 prescriptions per year. A much smaller and statistically insignificant increase in Vyvanse prescribing was observed in states without marketing regulation. While peer influence was associated with a significant and clinically meaningful increase in prescribing rates of beneficial medications in states with marketing regulation, peer influence had no meaningful impact on Pristiq or Invega prescribing rates.

\subsection{Sensitivity analyses}

Models incorporating physician fixed effects assuaged concerns that targeting bias or other factors that do not change over time might explain our results. With physician fixed effects, the peer influence coefficient for Cymbalta was 1.08 ( $p<0.001$ ) and 1.15 $(\mathrm{p}<0.01)$ for Vyvanse in states than ban gifts to physicians. Using fixed effects, the peer influence variable for both Vyvanse and Cymbalta increases in magnitude and becomes significant in states with gift restrictions. In states with gift restrictions, the incidence rate ratio was $1.14(\mathrm{p}<0.01)$ for Vyvanse and $1.03(\mathrm{p}<0.01)$ for Cymbalta once physician fixed effects were included. Incorporating three-digit zip code fixed effects also did not substantially alter our results. Analyses of simulated peers further supported the notion that our models are capturing peer influence, not capturing events in the area such as conferences or promotional events. Models with randomly matched physicians practicing in the same area did not produce significant peer effects. While the main effects for gift bans, gift restrictions, and disclosure were largely unchanged, the interaction between peer influence and gift bans became insignificant. Using randomly matched "peers" practicing in the same zip code, the interaction between gift bans and peer learning was 1.01 $(\mathrm{p}=0.12)$ for Vyvanse and $1.02(\mathrm{p}=0.08)$ for Cymbalta. These coefficients are much smaller than the coefficients in our primary models and are statistically insignificant (See Supplementary Appendix for models.).

Two additional factors increased our confidence in our results. First, we observed elevated peer influence in areas with limited marketing influence. Second, we only saw significant peer effects for efficacious drugs. If homophily (which would manifest here as the tendency of doctors with similar prescribing behavior to be peers) accounted for the peer effects in our model, we would not expect it to express itself only on efficacious medications. Any alternative explanation of our results must simultaneously account for the stronger expression of peer effects in areas with stringent marketing regulation and only when the drug is efficacious.

Finally, our results are robust to alternate measures of physician peers. Using patient-sharing networks to define peers, we found results consistent with those reported above. The size of the interaction term between peer influence and gift bans for Vyvanse, however, was substantially larger when patient-sharing was used to define peers. For Cymbalta, the interaction term was 1.10 $(p=0.01)$ when proxying for peer networks and $1.13(p=0.03)$ when peer influence was defined based on patient-sharing networks. For Vyvanse, these coefficients were $2.08(\mathrm{p}=0.03)$ when using patient-sharing networks and $1.11(\mathrm{p}<0.001)$ when using the peer proxy. This substantial difference in Vyvanse coefficients may arise from one doctor refilling a Vyvanse prescription written by a peer for a shared patient. The coefficients for the regulatory variables and baseline peer influence variables were similar across both models for all medications. These results increased our confidence that the measure of peer influence, which relies on proximity, medical school attendance, and specialty, is a reliable approximation of peer influence processes.

\subsection{Causality, mechanisms, and alternative explanations}

Since we do not have data on prescribing behavior pre- and post-policy implementation, it is difficult to establish whether the policy itself accounts for the observed association between regulatory environment and lower prescribing rates or whether there is something different about these states that lead them to adopt policies regulating pharmaceutical marketing activity and to have lower prescribing rates irrespective of the policy. To rule out competing explanations, we conducted three additional analyses.

First, we conducted a supplementary analysis that included an indicator to examine prescribing behavior in Colorado. In 2006, legislation that would have required and made public disclosures of payments to physicians passed both the state house and senate but was vetoed by the Governor. If political climate or practice preferences accounted for the observed variation by regulatory environment, we would anticipate lower rates of prescribing in Colorado relative to states that had not passed marketing legislation. A robustness check found no evidence that this was the case: the incidence rate ratio in Colorado for Vyvanse was 0.87 (95\% C.I: $0.65,1.15)$, Pristiq was 0.76 (95\% C.I: $0.55,1.04)$, Invega was 1.30 (95\% C.I: $1.11,1.52)$, and Cymbalta was $0.91(0.80,1.04)$. We were also obtained additional data for antipsychotics for the period following Vermont's strengthened marketing regulation, which allowed us to observe prescribing rates of Invega prior to and after the stronger policy took effect. A comparison of prescribing behavior pre- and post-policy implementation is striking. Following the enactment of a more stringent policy, which banned all gifts, prescribing rates of Invega dropped by half and never reached their previous levels. Finally, our results are robust to the inclusion and exclusion of Massachusetts in the gift ban category in 2009.

Differences in market share across the different regulatory environments could potentially be explained by insurance formularies and payer behavior. However, average copayments across regulatory environments cannot explain our findings. Surprisingly, copays in states with gift bans actually tend to be lower than copays in states with weaker or no detailing regulation.

Finally, it is worth noting that the peer influence we observe cannot simply be explained by key opinion leaders. Recall, that we only observe elevated peer influence effects in states with gift bans. Gift bans would apply to all physicians practicing in the state-including potential key opinion leaders. In addition, we control for prescribing volume which is the primary metric used by pharmaceutical companies to identify key opinion leaders. Any potential remaining effect of key opinion leaders would also be captured in our analyses using simulated peers. We do not observe peer influence when using randomly matched peers. Lastly, it seems unlikely that pharmaceutical companies would only use key opinion leaders to market efficacious medications. Rather, in a world where key opinion leaders were driving the peer influence effect, we would expect to see a significant effect for all medications. Collectively, this evidence suggests that the peer influence we observe comes from physicians sharing beneficial information 
about clinically advantageous drugs with other physicians, not from paid key opinion leaders.

\section{Discussion}

A growing body of work suggests that detailing has a significance influence on physician prescribing behavior (Fleischman et al., 2016). This is why, of course, the pharmaceutical industry spends billions of dollars a year on detailing. Our work finds that regulatory regimes that curtail such largess turn out to benefit consumers, since in the absence of gifts, dinners, honoraria, pens, trips, free samples, and other inducements, physicians are less likely to prescribe costly new medications that have few advantages over existing alternatives. Instead, we find that when conflict of interest policies restrict detailing, physicians turn to other physicians for advice about new drugs, select drugs that work and ignore those that do not.

To curb the conflicts of interest generated by detailing, academic medical centers, individual practices, hospitals, states, and nations have enacted various policies including gift bans, gift restrictions, and various forms of disclosure. Mounting evidence suggests that medical school conflict of interest policies have a significant impact on prescribing (King et al., 2013; Epstein et al., 2013; Larkin et al., 2014). This work has also found that more restrictive policies have a stronger effect on prescribing. However, little empirical research has examined the relative efficacy of different types of conflict of interest policies.

Our work extends previous research by comparing the impact of different policies on prescribing rates. All three policy instruments we examined were associated with reductions in prescribing. However, we observe the largest reductions in prescribing in states with ban gifts and gift restrictions. Disclosure policies that did not reveal physicians' identities also reduced new drug uptake but were less effective than other policy instruments. These findings stand in contrast to previous work which suggests that gift-limits and disclosure requirements are unlikely to be effective (Dana and Loewenstein, 2003; Sah and Fugh-Berman, 2013). While our work makes progress towards comparing the relative efficacy of different policy mechanisms, we are unable to observe the full range of policy options. For instance, we do not observe the effect of public disclosure in isolation nor do we observe ironclad gift bans that do not have exceptions for samples and the like.

Despite mounting evidence that policies restricting interactions between pharmaceutical companies and physicians effect prescribing behavior, whether these policies effect the quality of care patients receive remains largely unknown. We help address this gap in the literature by examining variations in prescribing rates of medications that differ in clinical benefit. Marketing regulation was not associated with a simple reduction in prescribing for all medications. For medications that did afford advantages over other drugs already on the market, peer networks offered an alternative means by which information about new drugs diffused when regulations were in place restricting gifts. In states where gift giving was prohibited, the importance of peer influence was exacerbated. Peer influence was of the greatest importance in states with gift bans when an effective drug came to market. Thus, our work makes an additional contribution to the literature by demonstrating that network-based social learning offers a less biased and more evidenced based mechanism for physicians to learn about new medications. However, it is worth noting that none of the medications we examined were radical breakthroughs. As a result, categorization of the efficacy of the medications in this study is difficult. Future work examining how marketing regulations effect the diffusion of truly innovative new medications is needed.

Our study has several important limitations that we hope future research will address. First, our study is limited in its ability to establish causality. The recent enactment of new state level policies and the Physician Payment Sunshine Act present valuable opportunities for future research to causally establish whether state and federal policies lead to changes in physician prescribing patterns. In addition, our data ends in 2009 so we cannot assess the effects these policies or more recent policies have on current physician prescribing. A second question our study has not addressed that warrants further investigation is how these policies work to reduce prescribing. For instance, do pharmaceutical companies reduce marketing efforts when faced with regulation or are physicians less likely to respond favorably to detailing when faced with disclosure? Finally, we do not have payments to individual physicians or aggregated marketing data for all companies. Future work examining how payments to doctors and conflict of interest policies affect patient outcomes and quality of care is needed. While reducing conflicts of interest is a laudable goal, ultimately the utility of these policies depends on whether they can reduce health care costs and improve patient outcomes.

Policymakers worldwide are searching for effective strategies to manage conflicts of interest that arise from physician-industry interactions. However, little empirical work exists to guide these policy choices. While all of the policy instruments we examined reduced physicians' propensity to prescribe newly marketed medications, our work suggests that gift bans coupled with mandatory public disclosure of exempt items are most effective at reducing prescribing rates of newly marketed medications.

\section{Appendix A. Supplementary data}

Supplementary data related to this article can be found at http:// dx.doi.org/10.1016/j.socscimed.2016.11.010.

\section{References}

Coleman, James, Katz, Elihu, Menzel, Herbert, 1957. The diffusion of an innovation among physicians. Sociol. Theory 20, 253-270.

Congressional Budget Office, 2009. Promotional Spending for Prescription Drugs 12-02-Drugpromo_brief.Pdf.

Dana, Jason, Loewenstein, George, 2003. A social science perspective on gifts to physicians from industry. JAMA J. Am. Med. Assoc. 290 (2), 252-255.

Duggan, Mark, 2005. Do new prescription drugs pay for themselves? J. Health Econ. 24 (1), $1-31$.

Epstein, Andrew J., Busch, Susan H., Busch, Alisa B., Asch, David A., Barry, Colleen L., 2013. Does exposure to conflict of interest policies in psychiatry residency affect antidepressant prescribing? Med. Care 51 (2), 199-203.

Fleischman, William, Agrawal, Shantanu, King, Marissa, Venkatesh, Arjun, Krumholz, Harlan, McKee, Douglas, Brown, Douglas, Ross, Joseph S., 2016. Association between payments from manufacturers of pharmaceuticals to physicians and regional prescribing: cross sectional ecological study. BMJ 354, i4189.

Goesling, Jenna, 2013. Pain and depression: an integrative Review of neurobiological and psychological factors. Curr. Psychiatry Rep. 15 (12), 421.

Gorlach, Igor, Pham-Kanter, Genevieve, 2013. Brightening up: the effect of the physician payment sunshine act on existing regulation of pharmaceutical marketing. J. Law Med. Ethics A J. Am. Soc. Law Med. Ethics 41 (1), 315-322.

Kaiser Family Foundation, 2013. Total professionally active physicians. Total Prof. Act. Phys. Retrieved 10 November 2013 http://kff.org/other/state-indicator/ total-active-physicians/.

King, Marissa, Essick, Connor, Bearman, Peter, Ross, Joseph S., 2013. Medical school gift restriction policies and physician prescribing of newly marketed psychotropic medications: difference-in-differences analysis. BMJ Clin. Res. Ed. 346, f264.

Larkin, Ian, Ang, Desmond, Avorn, Jerry, Kesselheim, Aaron S., 2014. Restrictions on pharmaceutical detailing reduced off-label prescribing of antidepressants and antipsychotics in children. Health Aff. Proj. Hope 33 (6), 1014-1023.

Light, D.W., Lexchin, J.R., 2012. Pharmaceutical research and development: what do we get for all that money? BMJ 345 (aug07 1) e4348-e4348.

Light, Donald W., Lexchin, Joel, Darrow, Jonathan J., 2013. Institutional corruption of pharmaceuticals and the myth of safe and effective drugs. J. Law Med. Ethics 41.

Lunn, M.P., Hughes, R.A., Wiffen, P.J., 2009. Duloxetine for treating painful neuropathy or chronic pain. Cochrane Database Syst. Rev. 4 (2009), CD007115.

Manchanda, Puneet, Xie, Ying, Youn, Nara, 2008. The role of targeted communication and contagion in product adoption. Mark. Sci. 27 (6), 961-976. 
National Conference of State Legislatures, 2013. Marketing and Direct-to-consumer Advertising (DTCA) of Pharmaceuticals. Retrieved. http://www.ncsl.org/ research/health/marketing-and-advertising-of-pharmaceuticals.aspx.

Pew Charitable Trusts, 2013. "The Pew Charitable Trusts." Persuading the Prescribers: Pharmacuetical Industry Marketing and its Influence on Physicians and Patients. Retrieved 10 November 2013. http://www.pewhealth.org/otherresource/persuading-the-prescribers-pharmaceutical-industry-marketing-andits-influence-on-physicians-and-patients-85899439814.

Roskell, N.S., Setyawan, J., Zimovetz, E.A., Hodgkins, P., 2014. Systematic evidence synthesis of treatments for ADHD in children and adolescents: indirect treatment comparisons of lisdexamfetamine with methylphenidate and atomoxetine. Curr. Med. Res. Opin. 30 (8), 1673-1685

Sah, Sunita, Fugh-Berman, Adriane, 2013. Physicians under the influence: socia psychology and industry marketing strategies. J. Law Med. Ethics A J. Am. Soc. Law Med. Ethics 41 (3), 665-672.

Stuhec, Matej, Munda, Barbara, Svab, Vesna, Locatelli, Igor, 2015. Comparative efficacy and acceptability of atomoxetine, lisdexamfetamine, bupropion and methylphenidate in treatment of attention deficit hyperactivity disorder in children and adolescents: a meta-analysis with focus on bupropion. J. Affect. Disord. 178, 149-159.

Valentino, Joanne, 2004. Unbiased standard-of-care drug treatment guidelines now available on PDA. Med. Lett. 